\title{
Visual Interactive Syntax Learning: A Case of Blended Learning
}

\author{
Jane Vinther, ph.d., Institut for Sprog og Kommunikation, Syddansk Universitet
}

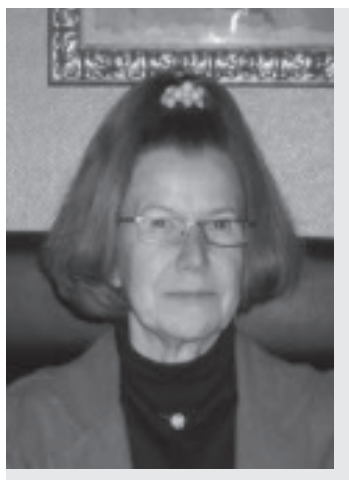

Jane Vinther is cand.mag. in English (major) and general pedagogy (minor). She holds a Ph.D. in computer-assisted language learning. Over the years she has been teaching a variety of subjects but now specialises in her research area of applied linguistics with a focus on second language acquisition and computer-assisted language learning.

The integration of the computer as a tool in language learning at the tertiary level brings several opportunities for adapting to individual student needs, but lack of appropriate material suited for the level of student proficiency in Scandinavia has meant that university teachers have found it difficult to blend the traditional approach with computer tools. This article will present one programme (VISL) which has been developed with the purpose of supporting and enhancing traditional instruction.

Visual Interactive Syntax Learning (VISL) is a programme which is basically a parser put to pedagogical use. The pedagogical purpose is to teach English syntax to university students at an advanced level. The programme allows the students to build sophisticated tree diagrams of English sentences with provisions for both functions and forms (simple or complex, incl. subclauses). VISL was initiated as an attempt to facilitate the metalinguistic learning process. This article will present VISL as a pedagogical tool and tries to argue the case for the benefits of blending traditional lecturing with modern technology while pointing out some of the issues involved.

\section{Introduction}

University lecturers have in the past been reluctant in their attitude towards the suitability of CALL, and for good reason as will be discussed below. What we need to discuss for the future, especially in linguistics, is not whether but how best to exploit the possibili- ties of new technology. The trend at present is that students enrol with highly developed communicative skills, but with increasingly low levels in accuracy and metalinguistic knowledge. The limitation in economic resources necessitates finding a way in which students in their own time with little guidance, for instance in collaborative teams, can be given a feasible possibility to achieve the level of knowledge we expect as it constitutes an underlying premise for keeping completion times and dropout rates in language programmes at a sustainable level.

Computer assisted language learning (CALL) is a many-faceted field, and it often means different things to different people depending on one's subject, and the level in the educational system at which one is engaged. In the primary section of the school system a host of educational programmes, or so-called courseware, is available in varying formats. At the tertiary level, however, it is harder to see CALL as an obvious choice due to limitations in the availability or suitability of courseware. Most of the good courseware is available only on commercially marketed CD-ROMs or through a subscription fee. As a consequence, much CALL instruction has been restricted to communication through chat-sites or e-mail. The advantage of this type of computer-mediated instruction has been its authenticity and potential usefulness for communicative training, but it has done little for the explicit knowledge of the advanced language learner and user at university level.

The benefits from the diversity of opportunities inherent in CALL have resulted in a plethora of approaches but often without sound foundations in empirical research and second language acquisition theory. Chapelle (1997) points out:" ...there is a need to specify the particularly relevant questions about CALL and to identify ways that can be investigated through empirical research." She continues, “... our understanding of CALL would benefit from addressing questions similar to those posed about other L2 ${ }^{1}$ classroom learning" (1997, p. 19). Common ground for CALL and second 
language acquisition (SLA) can be found for instance in the investigation of communicative competence, focuson-form (see Doughty \& Williams, 1998), vocabulary learning, the role of feedback, autonomous learning, and in specific and detailed issues which aim to investigate topics within each of these fields in more depth. For the formal aspects of language learning the outcome has been limited. Particularly language awareness and metalinguistic knowledge constitute areas which call for intensive, persistent, individualised and innovative solutions.

\section{CALL and English at the tertiary level}

In countries where the obligatory status of foreign language learning requires children to receive instruction from an early age, students will have achieved a relatively high level of proficiency at the school leaving age. This is the case for Denmark and other Nordic countries. Countries in which English is the native language may not see the same need for foreign language teaching and learning, and hence this type of instruction is initiated later and often on a selective basis. Consequently, the proficiency level will be lower when the transition from pre-university to university level takes place and this reflects on the use of CALL in the classroom.

When students enrol in the English study programme at a Danish university, they are no longer regarded as language learners in the fundamental sense of the term. Rather, they are users, albeit with a need for further development and guidance towards higher accuracy and a wider repertoire of expression. The curriculum bears comparison to literature, history, and social studies programmes in English speaking countries. The use of CALL applications and methodology in these programmes appears limited in these instances just as it does in English departments at Danish universities. A look at foreign language departments at universities in English speaking countries reveals a different situation. Here CALL is fast becoming an integral part of the range of tools and methodologies available to the language teacher (see Chapelle, 2001). Very few language teachers at universities in English-speaking countries do not avail themselves of CALL in one form or another (see Chapelle, 2003). The same is true for teachers of English as a foreign language in these countries, but one needs to bear in mind the proficiency level of these students as it is somewhat lower that that of the average Danish university students of English. Thus, it is difficult to draw parallels, and to stipulate that Danish university lecturers have been reluctant to see CALL as an option may not be the correct conclusion. Rather, the difficulty has been to find CALL courseware and material which would take into account context, learner fit, didactical concerns and resources.

\section{Availability and needs}

Multimedia CD-ROMs and other commercially marketed CALL materials (see McBride \& Seago, 1997) are available at levels ranging from beginning to advanced; they are usually very good but also very expensive. They vary in their didactic approaches, but their scope is usually general proficiency, or they may be aimed at English for special purposes, but hardly ever at the high level of proficiency and specialisation required for the very advanced university programmes that we find in the humanities in the Nordic countries.

A variety of freely available possibilities can be located on the web. They seem to fall in two categories: either multiple choice formats of stand-alone applications or they are connected to courses (in some cases text books) and home pages of individual teachers. A good example of the former is the internet-grammar website offered by University College London (http:// www.ucl.uk/internet-grammar). The site is thorough with a pleasing lay-out, easy to use, and it gives feedback. The drawback is that it cannot be customised, and the feedback is a standard text, which is the same irrespective of your correctness level, or the type of errors you make.The learning outcome would depend on the dedication and analytic abilities of the individual user. From an overall point of view, it is a 'drill-andkill' type of tool, and although it does accept student input in the form of ticking off one of two choice possibilities, its feedback makes it resemble a digital textbook.

The other type of website available is the one connected to a course book - or a particular course offered by individual teachers. Typically, the site would contain probing questions related to the various chapters or topics of the book. The purpose is that you can test yourself in how well you have been able to understand the subject matter of the course, but it is not a didactic tool aiming to play an active role in the learning process. The similarity to the textbook is striking and typically content-based, i.e. it is not aimed at language learners nor is its aim that users improve their interlanguage grammar. Rather, its context is a linguistics course whose students need to master a particular content. Finally, there are the "Ask Miss Grammar" type of sites which allow you to type in your question, which will be answered after a short period of time. This can be very useful, no doubt, but more like an e-mail exchange and not a systematic learning tool. This does not mean that it has no learning potential; in fact, it might be quite efficient from a learning point of view since it involves student input, interaction and speech acts. However, its scope is limited, there is no quality assurance, nor is the feedback immediate. There are sites created with the EFL ${ }^{2}$ learner in mind which contain good features for specific issues such as prepositions or verb tenses, but generally the level is too low for the very advanced university student in the Nordic 


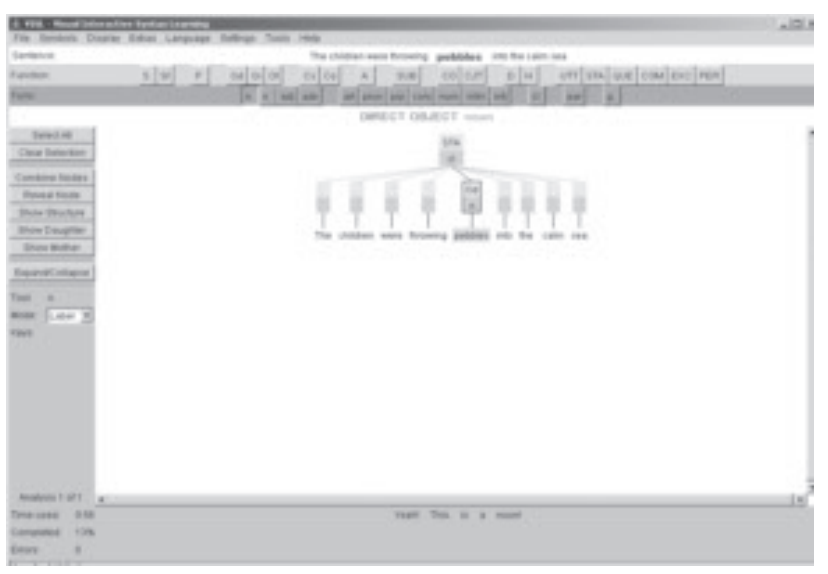

Figure 1. Screen print of the VISL tree-diagram interface

countries and as a rule they cannot be meaningfully applied in the English study programmes in the Nordic countries.

University-level language teachers of the linguistic disciplines are facing two issues which must give rise to concern. One is that the level of accuracy in language use seems to have been on a downward route, i.e. some awareness raising needs to occur. The other, and probably related issue, is the fact that students have very little metalinguistic knowledge. There is a need for instruction in linguistic concepts as well as a need to establish a common metalanguage. The concern and the need for supporting the formal aspects of language use and learning are increasingly giving rise to deliberation of ways which can alleviate the problematic consequences of such issues. Based on cohorts from New Zealand and Japan (Newman \& White, 1999) a study into the knowledge level of first year university students demonstrated that apart from nouns (identified by $75 \%$ ), no other parts of speech could be reliably identified (ibid., p.46). The study was motivated by "an expressed concern on the part of teachers of language-based courses (foreign languages, writing programmes, linguistics courses) about students' seemingly scant knowledge of language structure on entry to university courses" (ibid., p.41). Furthermore, it was the intention of Newman \& White to look behind the general conception of the alleged problems in order to establish whether beliefs were founded in real or imagined issues.

As reported above the issues were indeed real, as my own study (Vinther, 2008) showed. For the freshmen university students of language, there is a major task involved in establishing a common metalanguage as well as a sound foundation of metalinguistic knowledge. In this task there is little choice to be found in the number of suitable, interactive CALL tools and courseware. The question remains how best to meet these needs and there seems to be no ready answer. The student need for instruction and tools which may help raise their linguistic awareness to a level which makes them able to deal with the academic curriculum seems to be growing rather than the opposite. Consequently, it would be an advantage to all parties involved if student autonomy and its beneficial effects might be furthered through IT tools that could be used at the students' leisure outside as well as inside the classroom.

At the then Odense University, teachers and researchers struggling to find ways to meet these needs initiated the creation of what is now known as the VISL (Visual Interactive Syntax Learning) project.

\section{Visual Interactive Syntax Learning (VISL)}

VISL is a parser-based tool developed by researchers at the Institute for Language and Communication at the University of Southern Denmark on the basis of the constraint grammar formalism developed by Fred Karlson (1995), and further developed by Eckhardt Bick (2000; 2001). The initial motivation was a desire to help students in their efforts to apprehend English syntax and grammatical analysis, including the metalinguistic knowledge of the underlying grammatical concepts and the appropriate metalinguistic terms. The courses in this discipline are based on the textbook by Bache et al. (1999) and available in VISL in an interactive version. The free access to the web-based site (at http://beta.visl.sdu.dk) is an essential part of the attraction of VISL in that this is a pre-condition of individualised utilisation which makes for a profitable outcome in the light of the varying needs of the students. The interface best suited to the curriculum in the English study programme is the one featuring the tree-diagram building courseware in which the English syntactical structure as well as parts of speech can be trained.VISL has the advantage that it responds to student input by giving immediate feedback, which is essential in the learning process.

\section{The tree diagram interface}

The syntactical courseware in VISL deals with surface structure and keeps a strict division of function and form as does the basic text book attached to the course (see Bache et al. 1999). The interactive interface supports this distinction in that all the forms available are listed in the blue menu line at the top of the screen, and all the functions are listed in the green line (see Figure 1).

In the tree structure this corresponds to the blue square and the green square of the labelling box attached to each word of the sentence. This enhancement of features in the input is in accordance with the results from research which has demonstrated that various ways of enhancing features, e.g. by colouring or underlining, make features more salient and thus facilitate learn- 
ing (Sharwood Smith, 1993). The colouring scheme supports the student in her structure building part of the sentence analysis in that words become red when they have reached their final level, i.e. the structure is complete.

\section{Free text input or tagged corpus}

The VISL parser is quite advanced, and it is able to parse free text input of fairly complex sentences. Individual sentences can be typed into the text box but also entire paragraphs can be typed or pasted into the textbox. For the tree diagram interface, of course, it is only possible to operate with one sentence at a time, but for the flat structure - there is also an upload interface - larger pieces of text can be entered. The large tagged corpus in English contains authentic texts from novels, and textbook samples aimed at pre-university and university levels of the educational system. This means thatVISL can be applied both as a pedagogical and a linguistic tool, and hence it provides useful features for the graduate level as well as the post-graduate level.

\section{A sentence and its analysis}

In order to illustrate the elements of the tree-building function I have chosen the sentence illustrated in the screen print above (Figure 1) for comment on the various stages of the analysis (see also Figure 2 for selective illustration of three of these stages).

The analysis is attempted from a student's point of view. The first choice open to the student is whether to analyse the sentence or just to inspect the sentence. The option to inspect can be useful in several ways; if one has analysed a sentence and wants to check whether the analysis is correct or not, it is possible to check it here, or one can check particular structures of which one is uncertain. If the decision to analyse is made, the student chooses Build under the menu of Tools, and the starting screen looks like Tree 1. One word is red: "pebbles". The structure for this word is complete: it is the object. The other sentence constituents consist of several words that need to be organised into groups in order for the constituent to be presented in one node, or box, which then can be labelled. Tree 2 illustrates an attempt at building the adverbial group 'into the calm sea'. The student has been able to combine 'the calm sea' but so far failed to see that 'into' belongs to the group. The screen picture will show in two ways that the construction is incomplete. One general indication is that none of the words became red. A more specific indication, and one which is difficult to see in black and white print, is that the slant lines above 'into' and above the box presenting 'the calm sea' are grey, and not black, as they would otherwise have been if the
'The children were throwing pebbles into the calm sea'.

Tree 1.

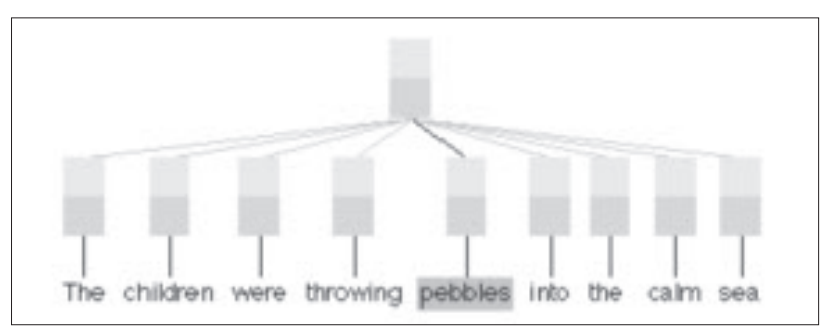

Tree 2.

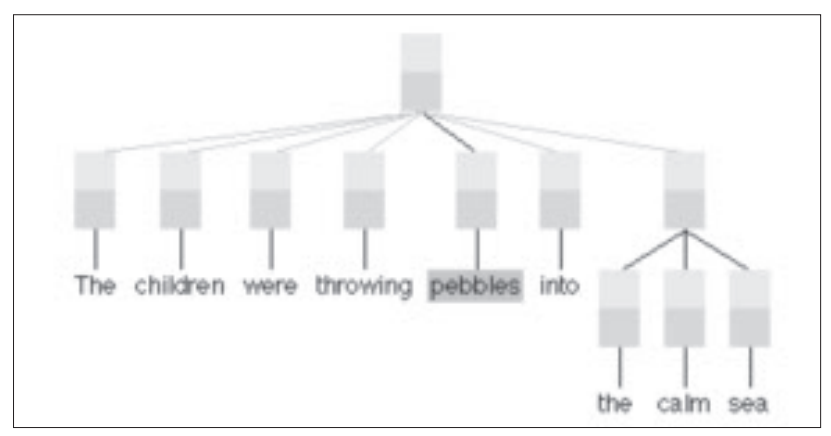

Tree 3.

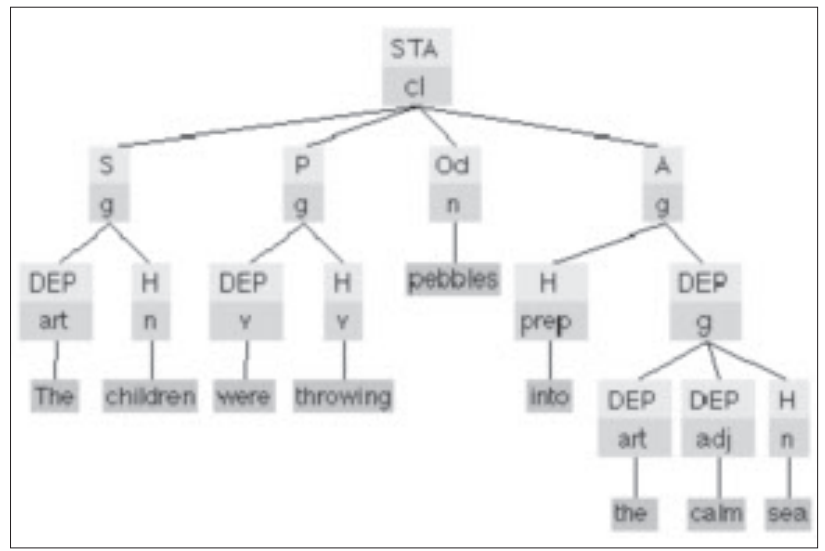

Figure 2. Three illustrative stages in the analysis of the example sentence.

structure had been complete. This tells the student that there is something amiss in the upper level. This immediate feedback should lead the student to complete the structure, and in addition make the student deliberate the structure of prepositional groups. The other words constituting the other constituents are combined and labelled in the same way until the entire structure is complete.

At the bottom of the screen (see Figure 1) there are other instruments of support. There is a time indicator telling the student how much time has been spent; there is an indication of the percentage of completion, and an indication of the number of errors made ${ }^{3}$. In addition, the bottom of the screen will have a running commentary directly pertaining to the input entered 
by the student, be it complementary or corrective. For instance, if a student were trying to label 'the' as an adverb the following comment would appear: "No. Adverbs are lexically loaded and they belong to an open word class. This form belongs to a closed word class" 4 . This is the type of feedback which forces the student to construct knowledge herself and which therefore may lead to learning. Tree 3 , the full picture, illustrates the interface when the tree has been successfully completed and all the function (e.g. S, P, O, A) ${ }^{5}$ and form (e.g. n, v, art, prep, etc. $)^{6}$ boxes filled. If a student should forget the meaning of the abbreviations, she would be told simply by pointing the cursor at it.

The learning potential of VISL was investigated in a comparative study involving a cohort of VISL users as well as a cohort of students in traditional classroom settings (Vinther, 2008). The results showed that VISL students were able to outperform the students in the NON-VISL group. Furthermore, there was an impact for the VISL cohort on the dropout rate, which was lower than for the comparable group in the traditional classroom. The study was carried out within the framework of the curriculum, which allowed for a combination, or blending, of the regular lecturing and the supporting VISL tool.

\section{Student expectations}

It goes without saying: efficacy is important. If no learning can be demonstrated, there is no further discussion. This does not mean, however, that efficacy is the only element of importance. There are other and equally legitimate concerns to be considered. Attracting students to the language programmes has been difficult in recent years, not only in Scandinavia. CALL could play a role in making our programmes up-todate and relevant to young people who have been used to the computer in pre-university education. We expect something from our students; the students also have expectations of us and the qualifications they will acquire at university. IT applied in relevant ways is among the expectations held by today's students. They furthermore expect to be met with individual options suited to their particular needs. VISL offers a qualified and highly relevant opportunity for living up to the best academic and pedagogical standards, including autonomous learning.

\section{Discussion}

VISL has the advantage of being web-based, which means that it can be accessed at any time that might suit the student. Thus the programme can initially be embedded in the common curriculum in a supporting function in the process of skill building. At a later stage the students can continue to work alone, or on a collaborative basis, on individual tasks, for instance in corpus work related to translation courses and other less specifically defined linguistic problem-solving tasks. At present it appears that especially the linguistic disciplines will be able to benefit from integrating CALL in the standard instructional setting. The strands in the university language programmes which concentrate on literature or history will not so easily lend themselves to computer-based instruction. The developmental stage of most CALL programmes makes them better suited to awareness-raising and skill-building activities. Further development towards more intelligent courseware materials which will meet the specific needs of the advanced language students, and which can be embedded in the curriculum (see Garrett, 1995, and Chapelle, 2001) is paramount. As mentioned above there is a shortage of suitable courseware, and a sustainable development requires an analysis of present and especially future needs.

VISL presents a viable option because it offers possibilities as a pedagogical tool as well as a linguistic tool. Its efficacy aside, it has the advantage of offering several possibilities for embedding in university curricula. Embedding is of vital importance for the authenticity of materials without which applications will be of no use to students or teachers. Consequently, the context of the curriculum must be the frame of reference in the decision-making process when considering new approaches and goals.

\section{Bibliography}

Bache, C., Davenport, M., Dienhart, J. \& Larsen, F. (1999). An Introduction to English Sentence Analysis. Copenhagen: Gyldendal.

Bick, E. (2000). The Parsing System Palavras - Automatic Grammatical Analysis of Portuguese in a Constraint Grammar Famework. Aarhus University, Aarhus. (pre-print version: http://beta.visl.sdu. dk/pdf/PLP20-amilo.ps.pdf and http://beta.visl.sdu.dk/pdf/ Disputatio.ps.pdf)

Bick, E. (2001).The VISL System: Research and applicative aspects of IT-based learning. In NoDaLiDa 2001. Uppsala.

Chapelle, C. A. (1997). CALL in the year 2000: Still in search of research paradigms? Language Learning \& Technology 1(1), 19-43.

Chapelle, C. A. (2001). Computer Applications in Second language Acquisition. Cambridge: Cambridge University Press.

Chapelle, C. A. (2003). English Language Learning and Technology. Amsterdam \& Philadelphia: John Benjamins.

Doughty, C. \& Williams, J. (Eds.). (1998). Focus on Form in Classroom Second Language Acquisition. Cambridge: Cambridge University Press.

Garrett, N. (1995). ICALL and Second Language Acquisition. In M. V. Holland, J. D. Kaplan \& M. R. Sams (Eds.), Intelligent Language Tutors (p. 345-358). Mahwah, NJ: Lawrence Erlbaum Associates.

Karlsson, F.,Voutilainen, A., Heiklilä, J., \& Anttila,A. (Eds.). (1995). Constraint Grammar: A Language-Independent System for Parsing Unrestricted Text. Berlin: Mouton de Gruyter.

McBride, N. \& Seago, K. (1997). Bridging the gap: Grammar as hypertext. ReCALL 9(2), 17-35.

Newman, J.W. \& White, Cynthia. (1999). A Pilot Study of Language Awareness at the New Zealand Tertiary Level. The New Zealand Language Teacher, 25, 41-53.

Sharwood Smith, M. (1993). Input Enhancement in Instructed SLA. Studies in Second Language Acquisition 15(2), 165-179. 
Vinther, J. (2008). Is interactive learning also active learning? A quantitative and qualitative study of computer assisted language learning. Unpublished Ph.D., University of Southern Denmark.

\section{Notes}

1 L2 (language two) is the accepted reference to any language other than one's mother tongue. It may in fact not be the second language since the term is also used to refer to language three etc. that a learner is acquiring.
2 English as a Foreign Language.

3 The student cannot enter incorrect labels; if a student wants to label a node subject, and it actually is the object, then it is not accepted, but the act is counted and indicated as an error. This means that the student receives immediate feedback, and it is also a safety net in so far as the student will never finish a tree with an incorrect structure or incorrect labelling.

4 This is the comment if one has ticked the semantics additional choice on the machine analysis structure.

5 For instance subject, predicator, object, adverbial.

6 For instance noun, verb, article, preposition, etc. 